\title{
THE
}

\section{Absolute Transports of Mass and Temperature for the North Atlantic Current-Subpolar Front System}

\author{
Paula Pérez-Brunius \\ Tom Rossby \\ University of Rhode Island \\ D. Randolph Watss \\ University of Rhode Island
}

Follow this and additional works at: https://digitalcommons.uri.edu/gsofacpubs

\section{Citation/Publisher Attribution}

Pérez-Brunius, P., Rossby, T., \& Watts, D. R. (2004). Absolute Transports of Mass and Temperature for the North Atlantic Current- Subpolar Front System. J. Phys. Oceanogr., 34, 1870-1883. doi: 0.1175/ 1520-0485(2004)034<1870:ATOMAT>2.0.CO;2

Available at: https://doi.org/10.1175/1520-0485(2004)034<1870:ATOMAT>2.0.C0;2

This Article is brought to you for free and open access by the Graduate School of Oceanography at DigitalCommons@URI. It has been accepted for inclusion in Graduate School of Oceanography Faculty Publications by an authorized administrator of DigitalCommons@URI. For more information, please contact digitalcommons-group@uri.edu. 


\title{
Absolute Transports of Mass and Temperature for the North Atlantic Current- Subpolar Front System
}

\author{
PAUla PÉReZ-Brunius \\ Woods Hole Oceanographic Institution, Woods Hole, Massachusetts \\ TOM Rossby AND D. RANDOLPH WATTS \\ Graduate School of Oceanography, University of Rhode Island, Narragansett, Rhode Island
}

(Manuscript received 2 April 2003, in final form 16 February 2004)

\begin{abstract}
The flow of subtropical waters carried into the northern North Atlantic Ocean by the North Atlantic Currentsubpolar front system (NAC-SPF) is an important component of the meridional overturning circulation. These waters become colder and denser as they flow through the subpolar region, both by mixing with the colder subpolar waters and by atmospheric cooling. The relative roles of these two processes remain to be quantified, and the mechanisms driving lateral mixing need to be better understood. To address those questions, a new methodology is developed to estimate the mean absolute transports of mass and heat for the top $1000 \mathrm{dbar}$ in the region of the NAC-SPF for the time period 1993-2000. The transports are obtained by combining historical hydrography with isopycnal RAFOS float data from the area. The mean absolute transport potential field shows an NAC-SPF "pipe," defined by two bounding transport potential contours. This pipe transports $10.0 \pm 3.5$ $\mathrm{Sv}\left(\mathrm{Sv} \equiv 10^{6} \mathrm{~m}^{3} \mathrm{~s}^{-1}\right)$ (top $1000 \mathrm{dbar}$ ) from the subtropics into the eastern subpolar North Atlantic. In contrast to earlier studies, the northward-flowing NAC follows a distinct meandering path, with no evidence of permanent branches peeling off the current before reaching the "Northwest Corner." As the current enters the Northwest Corner, it loses its tight structure and maybe splits into two or more branches, which together constitute the eastward flow along the SPF. The eastward flow between the Northwest Corner and the Mid-Atlantic Ridge is not as tightly defined because of the meandering and/or eddy shedding of the branches constituing the SPF. As the flow approaches the Mid-Atlantic Ridge, it converges to cross above the Charlie-Gibbs and Faraday Fracture Zones. The mean absolute temperature transport (top $1000 \mathrm{dbar}$ ) by the $10-\mathrm{Sv}$ pipe was estimated across 10 transects crossing the NAC-SPF. Because the mean mass flux is constant in the pipe, variations in the mean temperature transports result from lateral exchange and mixing across the pipe's side walls and from air-sea fluxes across the surface of the pipe. The NAC-SPF current loses $0.18 \pm 0.05 \mathrm{PW}$ on its transit through the region, most of the loss occuring upstream of the Northwest Corner. The heat loss is 10 times the corresponding heat lost to the atmosphere. We conclude that cross-frontal exchange induced by the steep meanders of the northward-flowing NAC is the main mechanism by which heat is lost along the current in the region between the "Tail of the Grand Banks" and the Mid-Atlantic Ridge.
\end{abstract}

\section{Introduction}

The North Atlantic Current-subpolar front system (NAC-SPF) serves as the main conduit of warm and salty water into the subpolar North Atlantic Ocean. It constitutes the upper limb of the thermohaline circulation of the North Atlantic Ocean, playing a crucial role in moderating the climate of northern Europe, and most likely has important implications for the general circulation of the atmosphere over a larger region of the Northern Hemisphere (e.g., Krauss 1986; Rossby 1996; Bower et al. 2000). On their transit through the subpolar

Corresponding author address: Paula Pérez-Brunius, Physical Oceanography Dept. MS \#34, Woods Hole Oceanographic Institution, Woods Hole, MA 02543-1541.

E-mail:pperez@whoi.edu region, the subtropical waters transported by the NACSPF cool and freshen by mixing with the adjacent subpolar waters and through wintertime convection (McCartney and Talley 1982). There is still much to be understood on the processes that transform the subtropical waters into intermediate and deep waters at higher latitudes, and the relative role of lateral mixing versus atmospheric cooling needs to be quantified.

Starting as a narrow and swift northward current, the NAC-SPF evolves into a broad and weak flow once it turns east past the "Northwest Corner" (Fig. 1, adapted from Bower et al. 2002). Much of our knowledge of the mean circulation in the subpolar North Atlantic comes from hydrographic studies, suggesting that the broad eastward flow consists of smaller baroclinic fronts, highly variable in space and time (e.g., Dietrich 


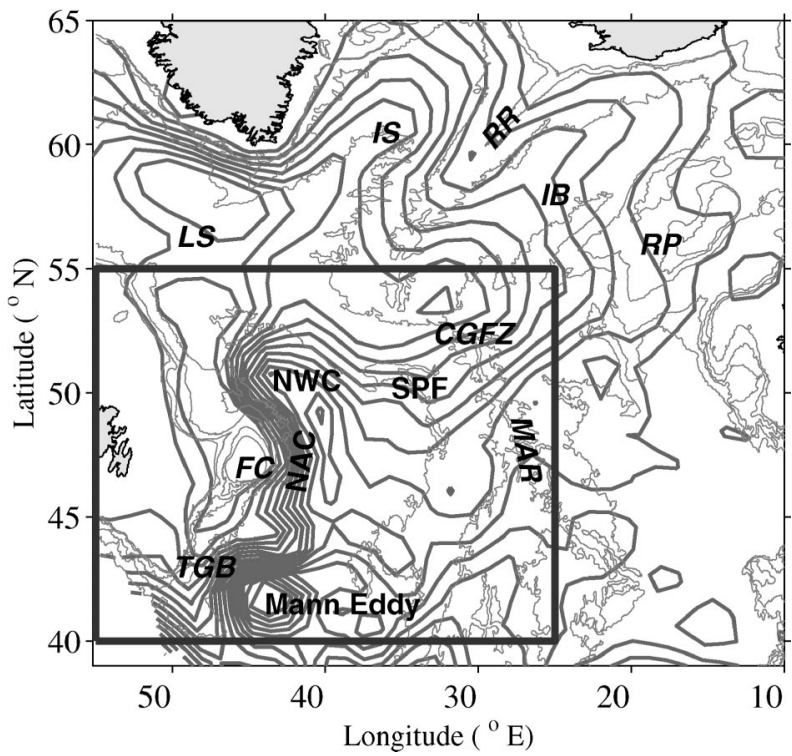

FIG. 1. Streamfunction map for the North Atlantic obtained from RA FOS floats on the 27.5- $\sigma_{\theta}$ surface using objective analysis to obtain the map on a grid made up by $111 \mathrm{~km} \times 111 \mathrm{~km}$ squares, adapted from Bower et al. (2002). Contours are drawn every $2.5 \times 10^{3} \mathrm{~m}^{2} \mathrm{~s}^{-1}$. Black box shows the region of study. Dynamical features are NAC: North Atlantic Current, NWC: Northwest Corner, and SPF: subpolar front. Topographic features are MAR: Mid-Atlantic Ridge, TGB: Tail of the Grand Banks, FC: Flemish Cap, CGFZ: Charlie-Gibbs Fracture Zone, RP: Rockall Plateau, IB: Iceland Basin, RR: Reykjanes Ridge, IS: Irminger Sea, and LS: Labrador Sea.

et al. 1980; Sy 1988; Arhan 1990; Belkin and Levitus 1996). It is believed that these fronts result from splitting of the northward-flowing NAC (at locations and frequencies yet uncertain). There have been many studies using hydrographic data and a level of no motion to provide estimates of the transport of the NAC-SPF cur- rent, but only a few estimates have used direct velocity measurements to estimate the absolute transport of the current, shown in Table 1. Meinen and Watts (2000) obtained the mean absolute transport carried by the northward-flowing NAC along a transect of moored current meters and inverted echo sounders (near $42^{\circ} \mathrm{N}$ ). From the same data, Meinen (2001) obtained the mean using stream coordinates. Those two studies are the only ones of which we are aware that provide a long-term mean of the absolute volume transport of the NAC. Downstream of this location, estimates of the absolute transport using direct velocity measurements are available for two more regions: the transport across part of the Northwest Corner, reported in Lazier (1994), and the mean eastward transport for the eastward flow along the SPF near the Charlie-Gibbs Fracture Zone obtained by Bubnov (1995). Note that the only study that provides an absolute temperature transport is that of Bubnov (1995).

In recent years, the circulation in the NAC-SPF region has been studied directly using Lagrangian drifters. Isopycnal float studies reveal a highly structured and localized eddy kinetic energy field. The northward flow of the NAC shows a pattern of topographically fixed meanders (Rossby 1996), whose amplitudes show fluctuations of $\sim 150 \mathrm{~km}$ (Kearns 1996). Bower et al. (2002) constructed the absolute streamfunction on the 27.5- $\sigma_{\theta}$ surface using the velocity measured by a large number of isopycnal RAFOS floats deployed in the region as part of the Atlantic Climate Change Experiment (Fig. 1). This map shows a rather different circulation pattern than the one suggested by the mean hydrographic field. On this density surface, it suggests 1) no splitting of the NAC upstream of the Northwest Corner, 2) a broadening of the flow in the SPF, and 3) a narrowing of the

TABLE 1. List of absolute transport estimates using direct velocity measurements for transects across the NAC-SPF current reported in the literature.

\begin{tabular}{|c|c|c|c|c|}
\hline Source & Volume (Sv) & Temperature (PW) & Layer & Time period \\
\hline \multicolumn{5}{|c|}{ NAC at $42^{\circ} \mathrm{N}$, including part of the Mann Eddy } \\
\hline This study* & 68 & 3.50 & $0-1000$ dbar & $\sim 2 \mathrm{yr}$ \\
\hline Meinen $(2001)^{* *}$ & 131 & - & Top to bottom & 19 months \\
\hline Meinen and Watts $(2000)^{*}$ & 146 & - & Top to bottom & 19 months \\
\hline Meinen et al. (2000) & 112 & - & Top to bottom & Snapshot \\
\hline \multirow[t]{3}{*}{ Reiniger and Clarke (1975) } & $123(93) \pm 50$ & - & $\begin{array}{l}\text { Top to bottom } \\
(0-2000 \mathrm{~m})\end{array}$ & Snapshot \\
\hline & $127(88) \pm 50$ & - & $\begin{array}{l}\text { Top to bottom } \\
(0-2000 \mathrm{~m})\end{array}$ & Snapshot \\
\hline & $112(76) \pm 50$ & - & $\begin{array}{l}\text { Top to bottom } \\
(0-2000 \mathrm{~m})\end{array}$ & Snapshot \\
\hline \multicolumn{5}{|c|}{ Across the Northwest Corner } \\
\hline Lazier $(1994)^{*}$ & 50 & - & Top to bottom & 8.5 months \\
\hline \multicolumn{5}{|c|}{ Eastward flow across $36^{\circ} \mathrm{W}$ between $47^{\circ}$ and $53^{\circ} \mathrm{N}$} \\
\hline This study* & 21 & 0.51 & $0-1000$ dbar & $\sim 2 \mathrm{yr}$ \\
\hline Bubnov (1995) & 64 & 1.99 & $0-2000 \mathrm{~m}$ & Snapshot \\
\hline
\end{tabular}

* Eulerian average.

** Mean was taken in stream coordinates. 
eastward flow as it approaches the Mid-Atlantic Ridge (MAR), crossing through the region of the Faraday and Charlie-Gibbs Fracture Zones. The anticyclonic recirculation cells of the Mann Eddy and Northwest Corner (see Fig. 1), and the narrowing of the current in the region of the MAR, have also been observed by surface drifters (Fratantoni 2001).

The discrepancy between the mean patterns of the baroclinic flow (i.e., derived purely from hydrography) and the absolute velocity field on the 27.5- $\sigma_{\theta}$ surface constructed by Bower et al. (2002) suggests that, in order to get an accurate view of the mean circulation and transports for the region, direct measurements of the flow are needed.

Perez-Brunius et al. (2004a) developed a technique (called float-Gravest Empirical Mode, or float-GEM) which combines the pressure measured by isopycnal floats with historical hydrography, in a similar fashion to the Gravest Empirical Mode method first applied by Meinen and Watts (2000). The float-GEM technique can be used to obtain the mean three-dimensional temperature and density fields (hence the baroclinic velocity field) for the time period of the float experiment. By making use of the velocity measured by the floats, the absolute velocity field, and hence the absolute transports of volume and temperature, can be estimated.

This study applies the float-GEM technique to two isopycnal RAFOS float experiments, carried out between 1993 and 2000, to map the mean absolute transport of mass of the NAC-SPF system for the region defined in Fig. 1 during that time period. Hence, the mean amount of water carried by the current from the subtropics into the subpolar region is quantified. We also calculate the downstream changes of the absolute temperature transport of the current, obtaining an estimate of the mean heat lost by the current's waters on their transit toward the subpolar North Atlantic. The relative roles played by the atmosphere and horizontal mixing in the ocean in determining that heat flux are examined. These results are of great interest from a climatic point of view.

\section{Data and methods}

\section{a. Float-GEM profiles}

We describe next how the float-GEM technique (Perez-Brunius et al. 2004a) is applied to isopycnal RAFOS float data and Gravest Empirical Mode (GEM) projections of historical hydrography available for the region. A RAFOS float is an acoustically tracked, neutrally buoyant drifter. A GEM field is a projection of hydrographic data onto geostrophic streamfunction space (Sun and Watts 2001). It captures most of the variability in the hydrographic field since horizontal motions of large-scale structures are stiff in the vertical direction (Sun 2001). We will use specific volume anomaly $(\delta)$ in this study since $\delta$ surfaces approximate neutral
TABLE 2. List of specific volume anomaly surfaces and their potential density analogs. Specific volume values in the first column are referenced to an intermediate temperature $\left(4.9^{\circ} \mathrm{C}\right)$ and salinity (34.6 psu). The second column has specific volume anomaly calculated using the standard $0^{\circ} \mathrm{C}$ and 35 psu values.

\begin{tabular}{ccc}
\hline \hline $\begin{array}{c}\text { Specific volume } \\
\text { anomaly } \\
\left(34.6 \mathrm{psu}, 4.9^{\circ} \mathrm{C}\right)\end{array}$ & $\begin{array}{c}\text { Specific volume } \\
\text { anomaly }\left(35 \mathrm{psu}, 0^{\circ} \mathrm{C}\right) \\
\left(10^{-8} \mathrm{~m}^{3} \mathrm{~kg}^{-1}\right)\end{array}$ & $\begin{array}{c}\text { Potential density } \\
\left(10^{-8} \mathrm{~m}^{3} \mathrm{~kg}^{-1}\right)\end{array}$ \\
\hline 70 & $\sim 142$ & $26.02)$ \\
60 & $\sim 134$ & $26.78 \sim 26.7$ \\
50 & $\sim 127$ & $26.89 \sim 26.9$ \\
40 & $\sim 119$ & $26.98 \sim 27.0$ \\
30 & $\sim 109$ & $27.08 \sim 27.1$ \\
20 & $\sim 93$ & $27.18 \sim 27.2$ \\
20 & $\sim 85$ & $27.28 \sim 27.3$ \\
0 & $\sim 71$ & $27.38 \sim 27.4$ \\
-10 & $\sim 64$ & $27.48 \sim 27.5$ \\
-20 & $\sim 57$ & $27.59 \sim 27.6$ \\
-30 & $\sim 43$ & $27.69 \sim 27.7$ \\
\hline
\end{tabular}

surfaces better than the more commonly used potential density (McDougall 1989). To help the reader, Table 2 shows various $\delta$ surfaces and their approximate potential density $\left(\sigma_{\theta}\right)$ counterparts. The $\delta$ values are referenced to $34.6 \mathrm{psu}$ and $4.9^{\circ} \mathrm{C}$, which are mean values for the region of the NAC-SPF (Kearns 1996).

The float data come from two isopycnal RAFOS float experiments: the NAC experiment (1993-95) and the Atlantic Climate Change Experiment (ACCE, 199799), both with the floats targeted for $\sigma_{\theta}=27.5$ (mean specific volume anomaly $\left.\delta_{\text {float }}=-5 \times 10^{-8} \mathrm{~m}^{3} \mathrm{~kg}^{-1}\right)$. We use 33 floats from the NAC experiment, deployed during three different cruises that took place in JulyAugust 1993, November-December 1993, and OctoberNovember 1994. Programmed to sample for 300 days, the floats collected position (and hence velocity), temperature, and pressure data two times per day (Anderson-Fontana et al. 1996). From the ACCE experiment, we use data from 50 floats deployed across the SPF during two cruises that took place in November 1997 and July 1998. These floats sampled position (and hence velocity), temperature, and pressure once a day, and their missions were 540 days long (Anderson-Fontana et al. 2001; Perez-Brunius et al. 2004a).

The velocity, temperature, and pressure records of both datasets were filtered by using a running-mean average with a window of $T_{L}=2.5$ days; $T_{L}$ corresponds to the Lagrangian correlation time scale derived for the region by Zhang et al. (2001). The data were then subsampled every 2.5 days to ensure statistical independence of the float data points. The combined ACCE and NAC data result in 14945 float observations, shown in Fig. 2.

We use monthly specific volume anomaly $\delta_{g}(\Psi, p)$ and temperature $T_{g}(\Psi, p)$ GEM fields constructed for 12 regions in the subpolar North Atlantic by PerezBrunius (2002, also see Perez-Brunius et al. 2004b), using more than 70 years of hydrographic data from 


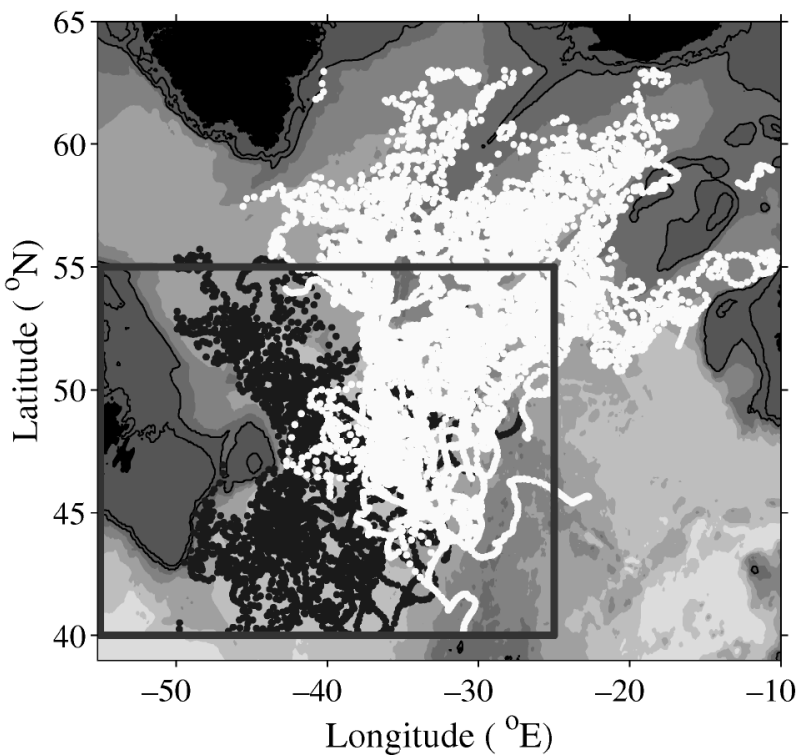

FIG. 2. Position of the RAFOS float stations used in this study. The black dots represent the float data from the NAC experiment (1993-95); the white dots show the float data points for the ACCE experiment (1997-2000). The black box shows the region studied.

HydroBase (Curry 1996, Fig. 3). The variable $p$ is pressure, and the geostrophic streamfunction $\Psi$ chosen to project the hydrographic data is the dynamic height at 200 dbar referenced to 1000 dbar.

Applying the float-GEM technique, profiles of specific volume anomaly $\delta_{\mathrm{fg}}(x, y, p)$ and temperature $T_{\mathrm{fg}}(x$, $y, p)$ are obtained at each float data point $(x, y)$. The subscript fg stands for float-GEM and serves as a reminder that $\delta_{\mathrm{fg}}$ and $T_{\mathrm{fg}}$ are estimates of the actual profiles of specific volume anomaly and temperature at the float data points, obtained by the procedure presented in Perez-Brunius et al. (2004a), which is briefly described as follows. The specific volume anomaly GEM field is used as a lookup table to estimate the value of the geostrophic streamfunction at each float data point $\left[\Psi_{\mathrm{fg}}(x, y)\right]$, by matching the known specific volume anomaly of the float $\delta_{\text {float }}$ with its measured pressure $p_{\text {float }}$, such that $\delta_{\text {float }}$ $=\delta_{g}\left[\Psi_{\mathrm{fg}}(x, y), p_{\text {float }}\right]$. Once the value of the geostrophic streamfunction $\Psi_{\mathrm{fg}}(x, y)$ is known, the corresponding specific volume anomaly and temperature profile at the float data point are estimated by making use of the corresponding GEM fields: $\delta_{\mathrm{fg}}(x, y, p)=\delta_{g}\left[\Psi_{\mathrm{fg}}(x, y), p\right]$ and $T_{\mathrm{fg}}(x, y, p)=T_{g}\left[\Psi_{\mathrm{fg}}(x, y), p\right]$. The subscript fg will be dropped from now on, understanding that all variables used after this point are estimates derived with the float-GEM technique, unless otherwise specified.

In addition, the floats independently measure the velocity at the specific volume anomaly surface of the floats: $\mathbf{V}_{\text {float }}\left[x, y, p\left(\delta_{\text {float }}\right)\right]$. From the specific volume anomaly profiles, the Montgomery streamfunction $\Pi$ referenced to $1000 \mathrm{dbar}$ is calculated on the $\delta_{\text {float }}$ surface:

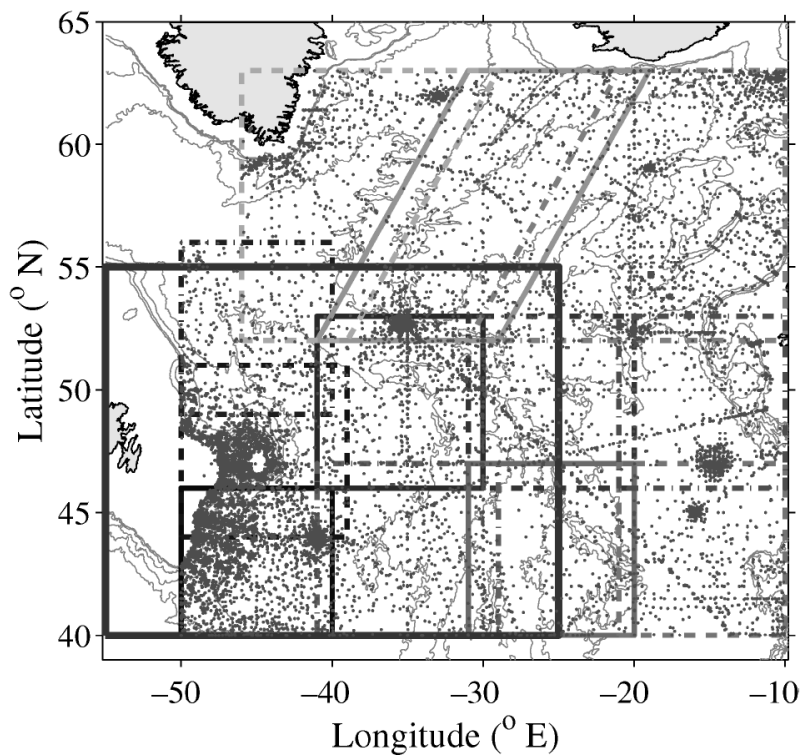

FIG. 3. Subregions for which monthly GEM fields of temperature and specific volume anomaly are available. Dots represent hydrographic stations from HydroBase used in their construction, obtained from Curry (1996). The large black box shows the region studied.

$$
\Pi=p_{\text {float }} \delta_{\text {float }}-\int_{1000 \text { dbar }}^{p_{\text {float }}} \delta d p .
$$

Divided by the Coriolis parameter $f$, the Montgomery streamfunction gives the baroclinic geostrophic streamfunction on the surface of the floats (McDougall 1989):

$$
\psi^{\mathrm{bc}}\left[x, y, p\left(\delta_{\text {float }}\right)\right]=\frac{\Pi}{f} .
$$

The baroclinic streamfunction at a given pressure level $p$ (relative to $1000 \mathrm{dbar}$ ) is given by

$$
\psi^{\mathrm{bc}}(x, y, p)=-\frac{1}{f} \int_{1000 \mathrm{dbar}}^{p} \delta d p^{\prime} .
$$

We also obtain the potential energy anomaly $\chi$ (referenced to $1000 \mathrm{dbar}$ ):

$$
\chi=-\frac{1}{g} \int_{1000 \mathrm{dbar}}^{0 \text { dbar }} p \delta d p,
$$

where $g$ is the acceleration of gravity (Fofonoff 1962). The potential energy anomaly divided by the Coriolis parameter $f$ gives the baroclinic transport potential for the top $1000 \mathrm{dbar}$,

$$
Q_{1000}^{\mathrm{bc}}=\frac{\chi}{f} .
$$

As a result, we have the following float-GEM dataset $\varphi=\left\{\delta(p), T(p), \mathbf{V}_{\text {float }}\left(\delta_{\text {float }}\right), \psi^{\mathrm{bc}}\left[p\left(\delta_{\text {float }}\right)\right], \quad \psi^{\mathrm{bc}}(p)\right.$, $\left.Q_{1000}^{\text {bc }}\right\}$ at each of the 14945 float stations of Fig. 2 with 0 dbar $\leq p \leq 1000 \mathrm{dbar}$. 


\section{b. Objective analysis}

We seek to obtain the mean fields of the float-GEM derived data $\{\varphi(x, y, p)\}$ on a selected geographical grid $\left\{x_{i}, y_{i}\right\}$. The general procedure is as follows: First, we bin the float-GEM data on an $n^{\circ} \times n^{\circ}$ grid covering the region of interest $\left(x_{b}, y_{b}\right)$, resulting in $\varphi\left(x_{b}, y_{b}, p\right)$. The standard deviation of the data in each bin is computed as $\varphi_{\mathrm{sd}}\left(x_{b}, y_{b}, p\right)$; it provides a measure of the variability not resolved by the binning. To interpolate the results into empty bins, as well as to get a smoother field, we use multivariate objective analysis (OA) following a procedure similar to the one presented by Watts et al. (2001, see appendix B). Note that the OA technique is a linear estimator; hence we can obtain the estimate of a linear operator applied to the variable of interest $\varphi$ from the same input data (Bretherton et al. 1976). This allows us to obtain the absolute streamfunction field at the specific volume anomaly surface of the floats $\psi^{a}\left[p\left(\delta_{\text {float }}\right)\right]$, using the float velocity data $\mathbf{V}_{\text {float }}$, assuming that the float's velocity is the absolute geostrophic velocity on its target surface $\delta_{\text {float }}$.

Since both baroclinic $\left(\psi^{\mathrm{bc}}\right)$ and absolute $\left(\psi^{a}\right)$ geostrophic streamfunctions on the specific volume anomaly surface of the floats are sampled at the same time and position, and interpolated in the same manner, the absolute streamfunction at the reference level can be obtained:

$$
\psi^{\mathrm{bt}}=\psi^{a}\left[p\left(\delta_{\text {float }}\right)\right]-\psi^{\mathrm{bc}}\left[p\left(\delta_{\text {float }}\right)\right]
$$

$\psi^{\text {bt }}$ is the "barotropic" streamfunction, which represents the absolute velocity field at the 1000-dbar reference level. This barotropic streamfunction needs to be added to the baroclinic streamfunction to obtain the absolute streamfunction field at all pressure levels $p$ sampled:

$$
\psi^{a}(p)=\psi^{\mathrm{bc}}(p)+\psi^{\mathrm{bt}},
$$

and our focus is upon $p \leq 1000 \mathrm{dbar}$.

Furthermore, the absolute transport potential $Q_{1000}^{a}$ for the top $1000 \mathrm{dbar}$ can be calculated as

$$
Q_{1000}^{a}=Q_{1000}^{\mathrm{bc}}+Q_{1000}^{\mathrm{bt}},
$$

where

$$
Q_{1000}^{\mathrm{bt}}=\rho D \psi^{\mathrm{bt}}
$$

is the "barotropic" transport potential, $D=1000 \mathrm{~m}$ is the height of the water column, and $\rho$ is the mean density of the water column $\left(\rho=1027 \mathrm{~kg} \mathrm{~m}^{-3}\right)$. By "barotropic" we mean the transport for the top 1000 dbar obtained from the barotropic velocity. Note that we are using the fact that $1 \mathrm{dbar}$ corresponds to $1 \mathrm{~m}$ within $1 \%$.

The absolute and baroclinic velocities $\left[\mathbf{V}^{a}(p), \mathbf{V}^{\mathrm{bc}}(p)\right]$ are derived from the corresponding streamfunctions $\left(\psi^{a}\right.$, $\left.\psi^{\mathrm{bc}}\right)$.

Last, the temperature transports $\left(H_{1000}\right)$ across a section is given by

$$
H_{1000}=\rho C_{p} \int_{0 \text { dbar }}^{1000 \text { dbar }} \int_{\text {section }} V_{l} T d l d z
$$

where $l$ is the distance along the section, $z$ is depth, $V_{l}$ is the velocity perpendicular to the section, and $C_{p}$ is the specific heat of seawater. We use $C_{p}=4 \times 10^{3}$ $\mathrm{J} \mathrm{kg}^{-1}{ }^{\circ} \mathrm{C}^{-1}$, and $\rho=1027 \mathrm{~kg} \mathrm{~m}^{-3}$. The baroclinic and absolute temperature transports are estimated from Eq. (10) using the corresponding velocities.

\section{Absolute transport maps}

To quantify the amount of water transported by the NAC-SPF system from the subtropics and into the subpolar North Atlantic, we proceed to calculate the baroclinic, barotropic, and absolute transport potentials for the region whose bounds are $40^{\circ}-55^{\circ} \mathrm{N}, 50^{\circ}-25^{\circ} \mathrm{W}$ by applying the interpolating method described in section $2 \mathrm{c}$ to the float-GEM data described in section 2a. The fields are binned and mapped on a $1^{\circ} \times 1^{\circ}$ grid $\left\{x_{b}\right.$, $\left.y_{b}\right\}$, applying the OA technique described in appendix $\mathrm{B}$, using $R_{b}=300 \mathrm{~km}$ for the background fields and $R_{r}$ $=150 \mathrm{~km}$ for the residual fields. These length scales are purposely chosen to be larger than the correlation scale appropriate to this region since we want a smooth map on which the largest features are enhanced. Figure 4 shows the number of float observations per bin and the corresponding histograms for the data distribution per month and per year. The NAC was mostly sampled between 1993 and 1995, and most of the data for the SPF region were sampled between 1997 and 1999. The summer months were the most undersampled of all, although no evident seasonal bias exists. Note that all transports reported from here on correspond to the top $1000 \mathrm{dbar}$ of the water column. We will use mass-Sverdrups $\left[10^{9} \mathrm{~kg} \mathrm{~s}^{-1}\right.$, corresponding to $10^{6} \mathrm{~m}^{3} \mathrm{~s}^{-1}(\equiv \mathrm{Sv})$ within about 3\%] as the unit to represent these transports.

\section{a. Baroclinic transport potential}

The resulting baroclinic transport potential field $Q_{1000}^{\text {bc }}\left(x_{b}, y_{b}\right)$ is shown in Fig. 5. The dark transport lines, corresponding to $Q_{1000}^{\text {bc }}=22$ and $34 \mathrm{~Sv}$, are shown as boundaries of the flow entering the region at the "Tail of the Grand Banks," and continuing eastward toward the MAR. The error of $Q_{1000}^{\mathrm{bc}}$ is $1.2 \mathrm{~Sv}$ (see appendix A).

Figure 5 suggests a broadening of the northwardflowing NAC that starts to occur upstream of Flemish Cap and continues as the current approaches the Northwest Corner. The baroclinic field has been estimated in previous studies, most of them derived from climatologies constructed from historical hydrography (e.g., Iselin 1936; Lozier et al. 1995; Kearns 1996). This component has also been calculated by combining the float data from the NAC experiment with historical hydrography, using the strong correlation between the pressure of the target isopycnal of the floats and the potential energy anomaly fields (Kearns 1996; Carr et al. 1997; Perez-Brunius et al. 2004a). In all cases, the resulting patterns show an eastward flow about $700 \mathrm{~km}$ wide, 

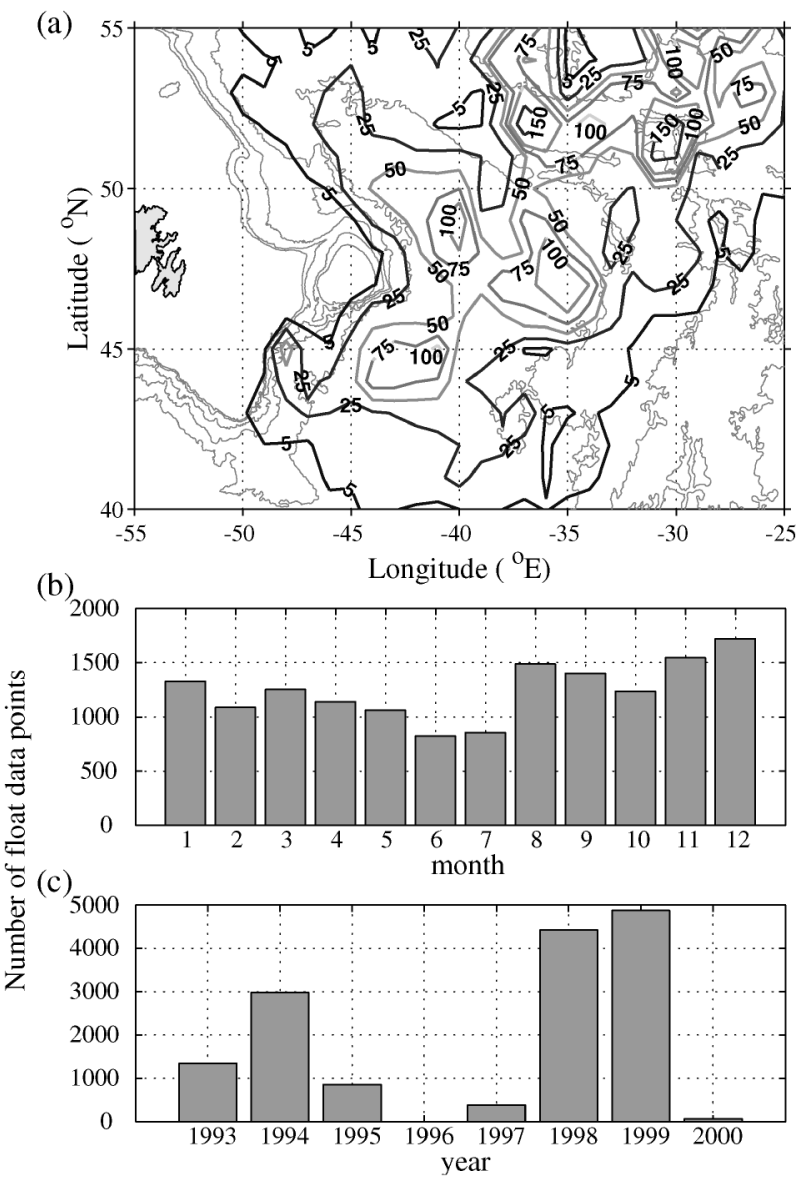

FIG. 4. (a) Number of float data points per $1^{\circ} \times 1^{\circ}$ bin. (b) Histogram of float data points per month. (c) Histogram of float data points per year. Most data were collected between 1993 and 1995 in the NAC, and the SPF was mostly sampled during 1997-99. There is no evident seasonal bias. The summer months were the least sampled of all.

from $46^{\circ}$ to $52^{\circ} \mathrm{N}$. Synoptic hydrographic surveys have observed the eastward flow to the north of $46^{\circ} \mathrm{N}$ associated with two or more smaller baroclinic fronts, highly variable in space and time, which we here refer to as the SPF (Sy 1988; Arhan 1990; Sy et al. 1992; Bubnov 1995; Belkin and Levitus 1996). Hence, one would expect that long-term Eulerian averages of these meandering and highly variable baroclinic structures will smear out the fronts, resulting in what appears as a broad and slow eastward drift.

The baroclinic flow transports a total of $\sim 12 \mathrm{~Sv}$ from the Tail of the Grand Banks into the eastern subpolar region, crossing the MAR between $46^{\circ}$ and $53^{\circ} \mathrm{N}$. About $16 \mathrm{~Sv}$ of the northward flow entering the region at $40^{\circ} \mathrm{N}$ recirculates within the Mann Eddy, centered at $41^{\circ} \mathrm{N}$, $44^{\circ} \mathrm{W}$.

\section{b. Barotropic transport potential}

Figure 6 shows the barotropic transport potential $Q_{1000}^{\mathrm{bt}}\left(x_{b}, y_{b}\right)$ for the top $1000 \mathrm{dbar}$. The error of $Q_{1000}^{\mathrm{bt}}$

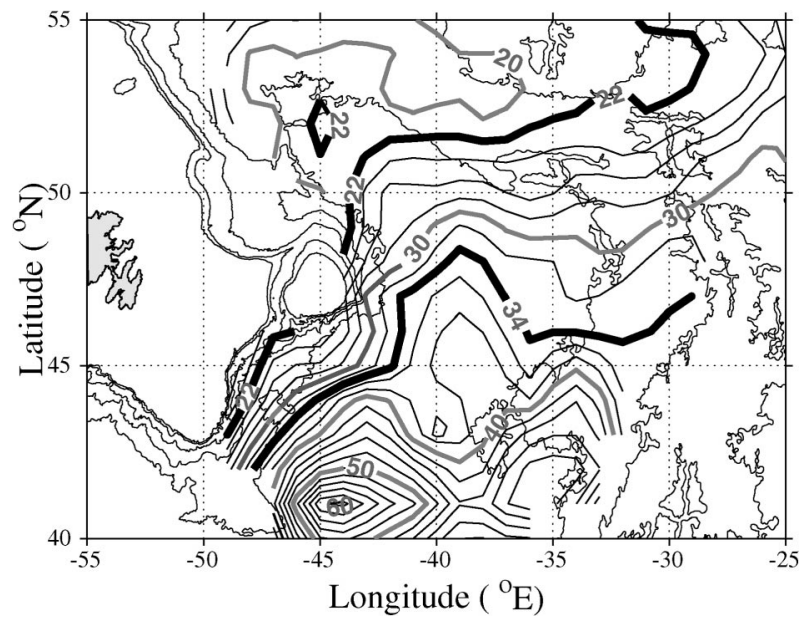

FIG. 5. Baroclinic transport potential for the top $1000 \mathrm{dbar}$, relative to $1000 \mathrm{dbar}\left(Q_{1000}^{\mathrm{bc}}\right)$, shown in mass-Sverdrups $=10^{9} \mathrm{~kg} \mathrm{~s}^{-1}$, which correspond to $1 \mathrm{~Sv}=10^{6} \mathrm{~m}^{3} \mathrm{~s}^{-1}$ to within $3 \%$. The difference between contour values is a measure of the transport in mass-Sverdrups between those contours. The two thick black lines show the boundaries of the warm water flow entering the region at the Tail of the Grand Banks and continuing eastward toward the MAR. The flow is about $200 \mathrm{~km}$ wide as it enters the region, and it broadens as it continues eastward, having an envelope of about $700 \mathrm{~km}$ and a transport of 12 $\mathrm{Sv}$. Light gray contours are every $10 \mathrm{~Sv}$, and thin black contours are every $2 \mathrm{~Sv}$. Error in $Q_{1000}^{\text {bc }}$ is $1.2 \mathrm{~Sv}$.

is $3.3 \mathrm{~Sv}$ (see appendix A). Noteworthy are the three recirculating cells surrounding the northward-flowing NAC: two anticyclonic cells, the Mann Eddy (centered at about $41^{\circ} \mathrm{N}, 44^{\circ} \mathrm{W}$ ) and the Flemish Cap-Northwest Corner recirculation (centered around $51^{\circ} \mathrm{N}, 42^{\circ} \mathrm{W}$ and extending south to $\sim 46^{\circ} \mathrm{N}$ ), and one cyclonic cell found inshore of the NAC south of Flemish Cap, which includes a trough centered at $\sim 44.5^{\circ} \mathrm{N}$.

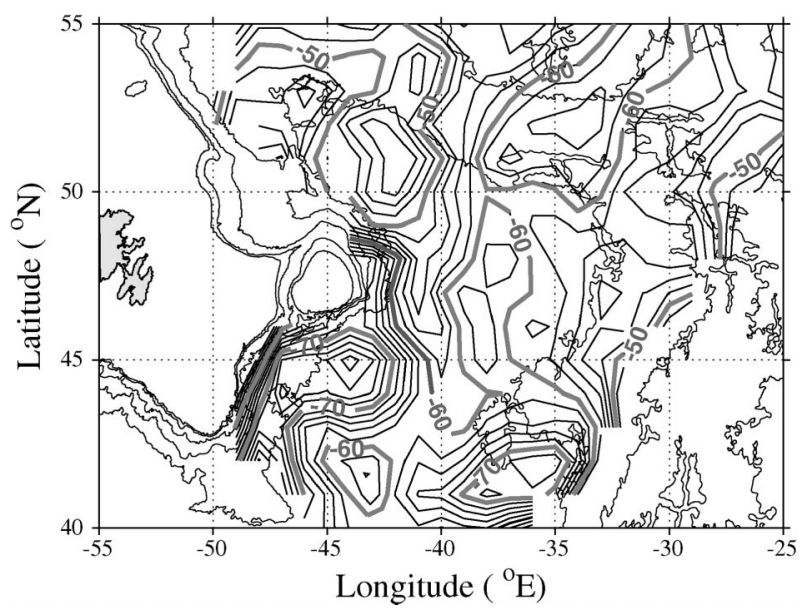

FIG. 6. Barotropic transport potential for the top $1000 \mathrm{dbar}$ $\left(Q_{1000}^{\text {bt }}\right)$. Noteworthy are the recirculations found surrounding the northward-flowing NAC: the Mann Eddy centered at $42^{\circ} \mathrm{N}, 44^{\circ} \mathrm{W}$; the cyclonic cell inshore of the NAC, including the trough at $44^{\circ} \mathrm{N}$; and the Northwest Corner-Flemish Cap extending from $45^{\circ}$ to $52^{\circ} \mathrm{N}$. Light gray contours are every $10 \mathrm{~Sv}$, and thin black contours are every $2 \mathrm{~Sv}$. Error in $Q_{1000}^{\mathrm{bt}}$ is $3.3 \mathrm{~Sv}$. 


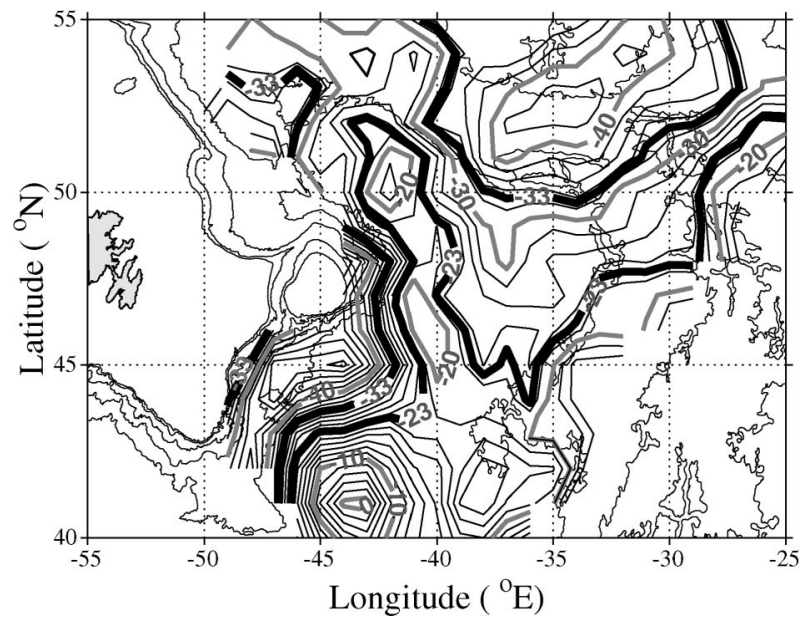

FIG. 7. Absolute transport potential for the top $1000 \mathrm{dbar}\left(Q_{1000}^{a}\right)$ The NAC-SPF appears as a well-defined current, flowing north along a meandering path, and then turning eastward past the Northwest Corner. Note that there is no evidence of splitting into permanent branches upstream of the Northwest Corner. Also noteworthy is the convergence of the transport contours as the flow approaches the MAR, crossing above the region of the Charlie-Gibbs and Faraday Fracture Zones. The boldface black isolines represent the boundaries of the NAC-SPF pipe that transports $10 \mathrm{~Sv}$ from the subtropics into the eastern subpolar North Atlantic. Light gray contours are every $10 \mathrm{~Sv}$; thin black contours are every $2 \mathrm{~Sv}$. Error in $Q_{1000}^{a}$ is $3.5 \mathrm{~Sv}$.

The Mann Eddy has a barotropic transport of $\sim 6 \mathrm{~Sv}$. The cyclonic recirculation reflects the Labrador Current flowing southward through the opening between the Grand Banks and Flemish Cap, turning northward as it encounters the NAC at the Tail of the Grand Banks. The trough at $44.5^{\circ} \mathrm{N}$ has been reported before (e.g., LaViolette 1983; Krauss 1986), but it is particularly extended to the east for the period sampled by the NAC floats (1993-96; Rossby 1996; Kearns and Rossby 1998). This cyclonic cell recirculates about $8 \mathrm{~Sv}$ in the top 1000 dbar.

The Northwest Corner appears as a well-defined eddy, the anticyclonic flow around it extending south to Flemish Cap. It recirculates about $10 \mathrm{~Sv}$. Previous studies have also found a detached eddy in the Northwest Corner (e.g., Lazier 1994; Kearns 1996; Fratantoni 2001).

The barotropic transport east of $40^{\circ} \mathrm{W}$ suggests the presence of three cyclonic recirculations: one centered at $41^{\circ} \mathrm{N}, 37^{\circ} \mathrm{W}$, another centered at $38^{\circ} \mathrm{W}$ extending from $44^{\circ}$ to $49^{\circ} \mathrm{N}$, and the last one centered at $52^{\circ} \mathrm{N}, 35^{\circ} \mathrm{W}$. Near the MAR, the barotropic transport isolines converge into a northeastward flow, crossing the ridge between the Faraday $\left(50^{\circ} \mathrm{N}\right)$ and Charlie-Gibbs $\left(52.5^{\circ} \mathrm{N}\right)$ Fracture Zones. This flow transports about $10 \mathrm{~Sv}$.

\section{c. Absolute transport potential}

The absolute transport potential $Q_{1000}^{a}\left(x_{b}, y_{b}\right)$, which is the sum of the baroclinic and barotropic transport potentials (Figs. 5 and 6), is shown in Fig. 7. The corresponding error is $3.5 \mathrm{~Sv}$ (see appendix $\mathrm{A}$ ). One feature that stands out is a continuous northward flow that turns east past the Northwest Corner and crosses the MAR between $48^{\circ}$ and $52^{\circ} \mathrm{N}$. The thick transport lines -33 and $-23 \mathrm{~Sv}$ indicate the boundaries of the aforementioned flow and represent the edges of the NAC-SPF. The selection of the boundaries of the current is somewhat arbitrary, since isolines within $\pm 2 \mathrm{~Sv}$ of the ones selected also connect the Tail of the Grand Banks with the Mid-Atlantic Ridge, but the selection is within the error bounds of the transport potential calculation (3.5 $\mathrm{Sv})$. The $-33 \mathrm{~Sv}$ line has a gap at the Northwest Corner, which we attribute to the presence of an eddy $\left(54^{\circ} \mathrm{N}\right.$, $42^{\circ} \mathrm{W}$ ) at the time when the floats were sampling the region. Also, that particular region has very few data points (see Figs. 2 and 4). Nevertheless, we believe the choice of the $-33 \mathrm{~Sv}$ contour elsewhere represents a good boundary for the cold side of the NAC-SPF current. Note that there is no evidence of branches splitting off the current upstream of the Northwest Corner. Rather, the NAC appears as a narrow current, about $50-100$ $\mathrm{km}$ wide, all the way from the Tail of the Grand Banks to Flemish Cap. It is not until entering the Northwest Corner that the current broadens, and maybe splits into more branches, before turning eastward. Just past the Northwest Corner (around $49^{\circ} \mathrm{N}, 38^{\circ} \mathrm{W}$ ), the eastward flow associated with the SPF is about $250 \mathrm{~km}$ wide. It seems to broaden even more, to about $500-600 \mathrm{~km}$ at $36^{\circ} \mathrm{W}$, but the transport lines converge as the flow approaches the MAR, crossing it in the region of the Faraday and Charlie-Gibbs Fracture Zones, where the eastward flow is about $150 \mathrm{~km}$ wide. This result is radically different from the baroclinic transport map of Fig. 5, where the NAC seemed to split and broaden to about $500 \mathrm{~km}$ far upstream of Flemish Cap, with the eastward flow associated with the SPF having an envelope around $700 \mathrm{~km}$ wide.

The fact that the flow across the MAR is constrained to the Faraday and Charlie-Gibbs Fracture Zones has been noted before (Arhan 1990; Sy et al. 1992; Fratantoni 2001; Bower et al. 2002), suggesting that topography has an important effect on "steering" the current into the subpolar region, despite the fact that the crest of the MAR is more than 1700 dbar below the sea surface.

The barotropic recirculations shape the absolute transport contours, by forcing flow across the baroclinic transport lines, both up- and downstream of the Northwest Corner. The cells appear in the absolute transport map, and recirculate $22 \mathrm{~Sv}$ in the Mann Eddy and $6 \mathrm{~Sv}$ in the cyclonic cell inshore of the NAC. The Flemish Cap-Northwest Corner recirculation appears as composed of two cells, each recirculating about $4 \mathrm{~Sv}$. One cell appears southeast of Flemish Cap between $44^{\circ}$ and $48^{\circ} \mathrm{N}$; the other is centered at $50^{\circ} \mathrm{N}, 42^{\circ} \mathrm{W}$. All transports are for the top $1000 \mathrm{dbar}$.

\section{d. Comparison with surface drifters}

Fratantoni (2001) and Reverdin et al. (2003) used the data from surface drifters to create the mean surface 


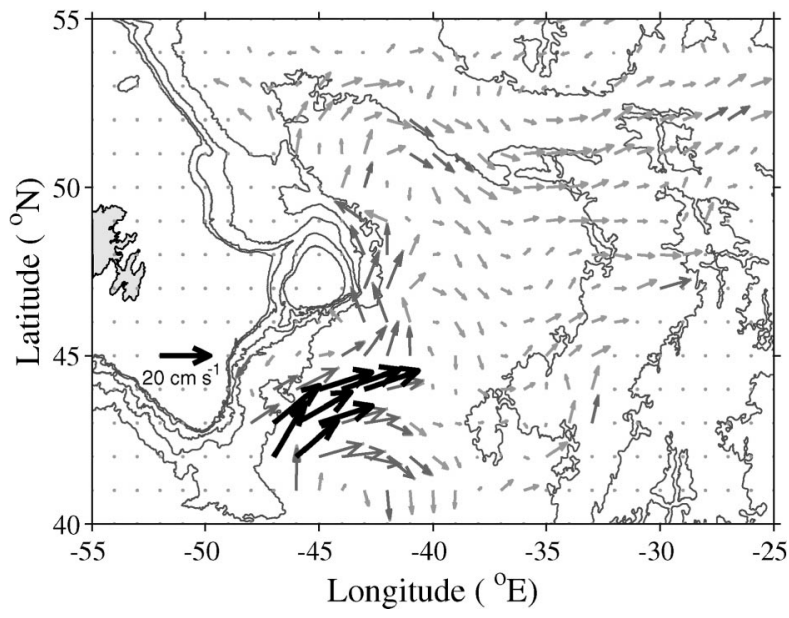

FIG. 8. Absolute velocity vectors at 15 dbar, derived from Eqs. (2), (3), (6), and (7). Black and dark gray arrows indicate velocity magnitudes larger than 20 and $10 \mathrm{~cm} \mathrm{~s}^{-1}$, respectively.

velocity vectors $(15 \mathrm{~m})$ for the North Atlantic. In order to compare our results with the ones obtained from the surface drifter dataset, the objectively mapped absolute velocity vectors from this study are shown in Fig. 8.

The largest mean velocities are observed in the NAC between $42^{\circ}$ and $44^{\circ} \mathrm{N}$ (speeds up to $25 \mathrm{~cm} \mathrm{~s}^{-1}$ ), while speeds between 10 and $20 \mathrm{~cm} \mathrm{~s}^{-1}$ are observed in the Mann Eddy, in the NAC between $45^{\circ}$ and $49^{\circ} \mathrm{N}$, and in the SPF just as it exists the Northwest Corner. The results from the surface drifters also find the largest velocities in the NAC upstream of Flemish Cap, although their magnitudes are larger than $30 \mathrm{~cm} \mathrm{~s}^{-1}$ there (Fratantoni 2001). High speeds are also observed off Flemish Cap, while the rest of the current has speeds between 15 and $30 \mathrm{~cm} \mathrm{~s}^{-1}$ (Fratantoni 2001). The magnitudes of our estimates are consistently smaller than the ones observed by the binned drifter data. This may be due to the smoothing imposed by the objective mapping of the mean binned fields (both of the geostrophic shear and the velocity at the reference level), resulting in an underestimation of the peak mean velocities. Another factor that may contribute to the difference is that drifter velocities may include the Ekman component of the flow, which is not captured by the geostrophic velocities shown in Fig. 8.

Nevertheless, the circulation patterns derived by the surface drifters and in this study are very similar. The Mann Eddy and Northwest Corner appear in the same locations, and the eastward current associated with the $\mathrm{SPF}$ is found between $49^{\circ}$ and $52^{\circ} \mathrm{N}$, crossing the MAR in the region between the Charlie-Gibbs and Faraday Fracture Zones. The trough at $44.5^{\circ} \mathrm{N}$ found in this study is also evident in the mean surface velocity map presented by Reverdin et al. (2003). A significant difference is that the anticylonic recirculation found east of the NAC between $44^{\circ}$ and $48^{\circ} \mathrm{N}$ in Figs. 7 and 8 appears as composed by two smaller cells in the study by Rev- erdin et al. (2003). The higher resolution of the mean maps presented by Reverdin et al. $\left(2003,0.5^{\circ}\right.$ latitude $\times 1^{\circ}$ longitude) may account for this difference.

\section{The NAC-SPF pipe}

Based on the results obtained in section 3c (Fig. 7), we will refer to the NAC-SPF as the conduit that transports $10.0 \pm 3.5 \mathrm{~Sv}$ of warm water in the top $1000 \mathrm{dbar}$ from the Tail of the Grand Banks into the Iceland Basin. In this sense, the NAC-SPF is seen as a pipe, whose walls are the absolute transport isolines $Q_{1000}^{a}=-33$ $\mathrm{Sv}$ on the cold side, $Q_{1000}^{a}=-23 \mathrm{~Sv}$ on the warm side of the current (Figs. 7 and 9a). We emphasize the fact that, although there is no mass transport through the walls of the pipe in the mean, at any point in time there is likely to be a net mass transport through the pipe's walls by the time-varying component of the flow. We will use the term "pipe" even though it may not be the most appropriate one given that the walls are not really material boundaries. The mean transport through the walls by the eddy-field is zero, and so mass is conserved in the mean within the pipe. Given this, the mean heat lost or gained by the NAC-SPF waters can be estimated by looking at changes in the mean temperature transport across the pipe. The NAC-SPF waters will get colder by losing heat to the atmosphere through the surface of the pipe $\left(H_{\text {flux }}^{\mathrm{atm}}\right.$ in Fig. 9a). On the other hand, the exchange of water between the pipe and its surroundings by the time-varying flow can result in a net mean temperature transport through the walls, resulting in a mean heat flux across the pipe $\left(H_{\text {flux }}^{\text {eddy }}\right.$ in Fig. $\left.9 a\right)$. The mean heat flux through the bottom of the pipe is neglected in this study. We also note that the warm water flow extends deeper, but this study only focuses on the top 1000 dbar.

To estimate the amount of heat lost by the NAC-SPF current as it flows through the region of study, 10 transects crossing the NAC-SPF pipe are selected (Fig. 9a). We note that transect 1 is chosen for comparison with the results obtained from a moored-array of instruments by Meinen and Watts (2000) and Meinen (2001) in the same location. The absolute velocity field and the temperature fields are obtained on each transect (located at $\left.\left\{x_{i}, y_{i}\right\}\right)$, applying the procedure described in section $2 \mathrm{~b}$. For this case, we obtain the background fields surrounding the transects on a $\left\{x_{b}, y_{b}\right\}=0.5^{\circ} \times 0.5^{\circ}$ grid, applying the OA technique described in appendix B with $R_{b}=150 \mathrm{~km}$. The geographical region $\left\{x_{b}, y_{b}\right\}$ used for the background field has a $2.5^{\circ}$ margin around the transect in question. The residuals are obtained for the background region and objectively mapped onto $\left\{x_{i}, y_{i}\right\}$ with the correlation length scale associated with the region $R_{r}=90 \mathrm{~km}$. The spatial resolution of the transect grid $\left\{x_{i}, y_{i}\right\}$ is $25 \mathrm{~km}$. Adding the value of the background fields, the final transect is obtained. Note that we have used a higher-resolution grid and smaller length scales for the OA mapping than the ones used for the 


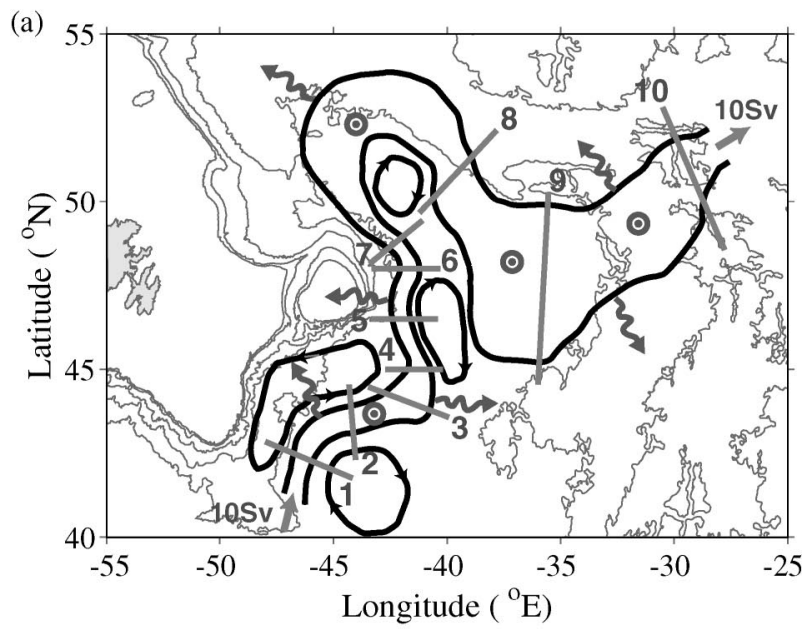

(b)

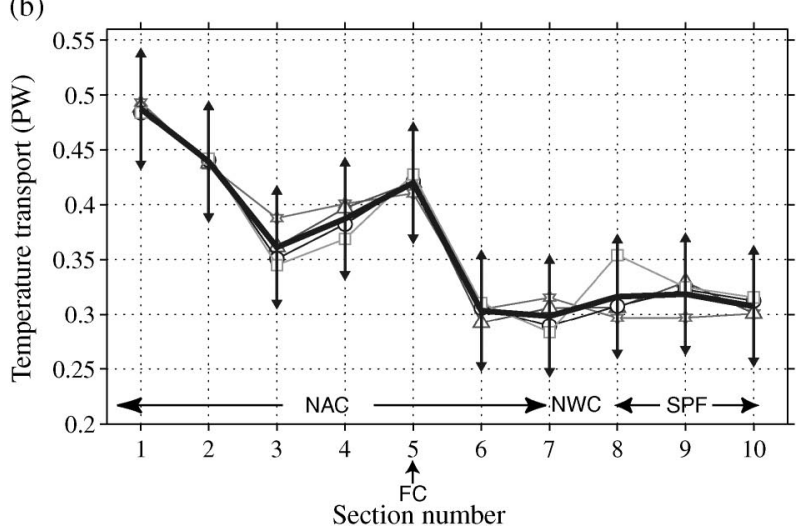

FIG. 9. (a) Cartoon of the NAC-SPF pipe, shown as the black contours consituting the two absolute transport potential isolines bounding the current. The pipe transports, in the mean, $10 \pm 3.5 \mathrm{~Sv}$ from the Tail of the Grand into the Iceland Basin. The waters within the pipe are getting cooled both by heat loss to the atmosphere ( $H_{\text {flux }}^{\text {atm }}$, represented by the updward pointing arrows in dark gray), and exchange across the walls induced by the eddy field $\left(H_{\text {flux }}^{\text {edd }}\right.$, represented by the wiggly arrows). The 10 transects used to calculate the temperature transport along the current are shown as the light gray lines. (b) Absolute temperature transports $H_{1000}^{a}$ along the NAC-SPF pipe $\left(\mathrm{PW} ;=10^{15} \mathrm{~W}\right)$. Symbols representing the temperature transport calculated for each mass transport potential pair are stars: $(-33,-23)$ Sv, triangles: $(-34,-24)$ Sv, circles: $(-35,-25)$ Sv, and squares: $(-36,-26) \mathrm{Sv}$. The boldface line is the mean temperature transport (taken over all pairs). Note the pattern of heat loss (gain) between crests (troughs) and troughs (crests) in the NAC. The error bars (vertical arrows) are due to the uncertainty in the float-GEM estimates of the temperature transports, and the standard deviation of the transports estimated from different transport potential pairs [see Eq. (11)].

construction of the maps of the previous section. The reason for this is that we want to capture most of the current's structure to obtain better estimates of temperature transport across the narrow pipe that constitutes the NAC-SPF current. This is possible given the higher data density in the area of these transects (Fig. 4). The transports of temperature are calculated between the boundaries of the NAC-SPF pipe $\left[Q_{1000}^{a} \in(-33 \mathrm{~Sv}\right.$, $-23 \mathrm{~Sv})]$.

\section{a. Transports along the NAC-SPF}

We now proceed to observe the changes in the temperature transports along the NAC-SPF pipe. Figure $9 \mathrm{~b}$ shows the transports of temperature corresponding to the $10 \mathrm{~Sv}$ of water flowing within the NAC-SPF pipe. The transports were calculated for four different pairs of absolute transport lines (each pair separated by 10 $\mathrm{Sv}$ ), to evaluate the sensitivity of the estimates to the somewhat arbitrary selection of the current's boundaries. The error bars are given by

$$
E H=\sqrt{\left(E^{t} H\right)^{2}+\left(E^{\sigma} H\right)^{2}},
$$

where $E^{t} H=0.05 \mathrm{PW}$ is the error in the temperature transports (see appendix A), and $E^{\sigma} H$ is the standard error for the mean temperature transport obtained for the four absolute transport potential pairs chosen:

$$
E^{\sigma} H=\frac{\sigma\left(H_{1000}^{\text {pairs }}\right)}{\sqrt{4}}<0.01 \mathrm{PW},
$$

with $\sigma\left(H_{1000}^{\text {pairs }}\right)$ being the standard deviation of the temperature transports. Therefore the calculation of the temperature transports is not very sensitive to the choice of the pipe's walls. The calculation was also done selecting $Q_{1000}^{a}=[(-33 \mathrm{~Sv},-23 \mathrm{~Sv}),(-34 \mathrm{~Sv},-23 \mathrm{~Sv})$, $(-35 \mathrm{~Sv},-23 \mathrm{~Sv}),(-36 \mathrm{~Sv},-23 \mathrm{~Sv})]$ to check for sensitivity of the heat fluxes between sections to different choices of the pipe's mean transport. The differences were smaller than the error of the estimates (not shown), and so given the precision of the method the choice of the boundaries of the NAC-SPF are irrelevant to the heat flux estimates.

The results show large changes in the temperature transports of the NAC upstream of the Northwest Corner (transects 1-6), while they remain nearly constant in the Northwest Corner and SPF (transects 7-10). A total of $0.18 \pm 0.05 \mathrm{PW}$ are lost between the Tail of the Grand Banks (transect 1) and Flemish Cap (transect 6). Past this point, no significant heat loss or gain is observed. In the northward-flowing NAC, a pattern of heat gain and loss emerges between meander extremes. Around $0.13 \pm 0.05 \mathrm{PW}$ are lost between the crest at $42^{\circ} \mathrm{N}$ (transect 1) and the $44^{\circ} \mathrm{N}$ trough (section 3 ), then a small heat gain $(0.06 \pm 0.05 \mathrm{PW})$ occurs between the $42^{\circ} \mathrm{N}$ trough (transect 3 ) and the crest off Flemish Cap (transect 5). Last, $0.12 \pm 0.05 \mathrm{PW}$ are lost between the crest of transect 5 and the following trough (transect 6).

\section{b. Transect 1: NAC at $42^{\circ} \mathrm{N}$}

Meinen (2001) used a transect of moored instruments (Clarke et al. 1996) to calculate the mean absolute velocity and temperature structure of the northward flowing NAC-SPF along transect 1 for the period between August 1993 and June 1995. The mean section is an average on "streamwise" coordinates; that is, each snapshot was centered at the high-velocity core of the stream and then averaged over time. We use the results 
from that survey to compare with the transports obtained in this study. The baroclinic transports for the top 1000 dbar across the transect are the same for both sections, which, including the Mann Eddy and the cyclonic recirculation inshore of the NAC, carry $40 \mathrm{~Sv}$ and $2 \mathrm{PW}$ toward the north. On the other hand, the absolute transports across transect 1 for the top 1000 dbar $(68 \pm 3.5$ Sv and $3.50 \pm 0.05 \mathrm{PW}$ to the north, including the Mann Eddy and cyclonic recirculations on both sides of the current) are $6 \%$ and $3 \%$ smaller than those estimated by Meinen (2001), respectively. This discrepancy is small, especially given the different methods and datasets used in calculating the mean transports.

\section{c. Atmospheric heat losses}

We can estimate the heat lost to the atmosphere $H^{\text {atm }}$ along the NAC-SPF pipe by

$$
H^{\mathrm{atm}}=W \times L \times H_{\text {flux }}^{\mathrm{atm}},
$$

where $W$ and $L$ are, respectively, the width and length of the NAC-SPF pipe between transects, and $H_{\text {flux }}^{\text {atm }}$ is the atmospheric heat flux in watts per meter squared. To estimate this flux, we consider the northward NAC flow ( $W \sim 100 \mathrm{~km}, L \sim 1000 \mathrm{~km}$ ) and the eastward flow associated with the SPF ( $W \sim 500 \mathrm{~km}, L \sim 1000$ $\mathrm{km}$ ) separately (see Fig. 9a). The mean atmospheric heat flux, estimated from the average for two full years (1998-99) of National Centers for Environmental Prediction-National Center for Atmospheric Research reanalysis data (Kalnay et al. 1996; Perez-Brunius 2002), is $H_{\text {flux }}^{\text {atm }} \sim(-200,-100) \mathrm{W} \mathrm{m}^{-2}$ in the NAC and SPF, respectively. This results in a total of $H^{\mathrm{atm}} \sim(0.02$, $0.05 \mathrm{PW}$ ) lost to the atmosphere by the NAC and SPF segments, respectively. Adding the two, approximately $0.07 \mathrm{PW}$ are lost to the atmosphere by the NAC-SPF waters on their transit through this region. Of course, this is a rather crude estimate considering the high seasonal and interannual variability in the atmospheric heat fluxes, as well as the uncertainty of the estimates of the atmospheric heat fluxes themselves. Nevertheless, the atmospheric heat flux for the NAC segment is an order of magnitude smaller than the heat lost by the current waters, estimated in section $4 \mathrm{a}$. This suggests that heat lost by lateral exchange across the side walls of the northward flowing NAC must play a dominant role in the mean cooling of the current's waters. To the level of accuracy of our estimates, no significant cooling occurs once the current enters the Northwest Corner, suggesting that most of the cooling of the waters carried by the NAC-SPF through the region of study takes place between the Tail of the Grand Banks and Flemish Cap.

\section{Discussion and summary}

The float-GEM technique (Perez-Brunius et al. 2004a) is applied to isopycnal RAFOS float data to ob- tain the mean three-dimensional temperature, specific volume anomaly, and absolute velocity field for the top $1000 \mathrm{dbar}$ of the NAC-SPF region. The technique combines the velocity and pressure records of the float data with projections on geostrophic streamfunction space of historical hydrography. The circulation patterns obtained for the region compare well to the ones observed by surface drifters (Reverdin et al. 2003), although the mean surface velocities (Fig. 8) are up to $50 \%$ smaller than the ones obtained from the binned surface drifter data (Fratantoni 2001). This discrepancy can be due to the smoothing introduced by the objective mapping and to effects of the wind on the surface layer not captured by our estimates.

The mean baroclinic and absolute transport potential fields were constructed for the top $1000 \mathrm{dbar}$ of the NAC-SPF region, representing the mean circulation of the warm waters for the 1993-2000 time period (Figs. 5 and 7). These two fields differ significantly: whereas the baroclinic transports in Fig. 5 suggest a broad and weak eastward flow, peeling off the northward-flowing NAC upstream of Flemish Cap, the absolute transports in Fig. 7 show a well-defined and narrow $(50-100 \mathrm{~km})$ northward-meandering current, with no evidence of splitting before reaching the Northwest Corner. The mean absolute transports estimated for the NAC at $42^{\circ} \mathrm{N}$ agree within $6 \%$ of the results obtained by Meinen (2001) from a moored array of current meters in the same transect. The tight structure of the mean NAC changes upon approaching the Northwest Corner where it widens as it turns eastward. The eastward flow is less organized, as can be seen from the wide envelope of the transport lines defining the SPF segment of the pipe. This may reflect the meandering and/or eddy shedding of the eastward flow associated with the SPF, which may be composed of several smaller branches. It is still not clear where the branches that compose the SPF originate. It has been hypothesized that they result from splitting of the northward-flowing NAC, some authors suggesting that the split occurs upstream of Flemish Cap (Dietrich et al. 1980; Krauss et al. 1987) while others think it may happen upstream, at, or past the Northwest Corner (Sy 1988; Arhan 1990; Lazier 1994). There is no clear evidence on how permanent or sporadic those branches are. This study suggests that the splitting or branching of the NAC does not occur upstream of Flemish Cap and that it is in the Northwest Corner where the northward NAC first broadens and maybe even splits into more branches. The eastward flow converges downstream to cross the MAR between the Faraday and Charlie-Gibbs Fracture Zones (Figs. 7 and 9a).

Why do the baroclinic transport pathways differ so from the absolute ones? We think this reflects the very different processes controlling the baroclinic and barotropic streamlines. The baroclinic velocity field depends on the density field, the shape of which reflects the following effects: First, the shoaling of isopycnals toward the north due to outcropping of the main ther- 
mocline of the subtropics along the boundary between the subtropical and subpolar gyres (which corresponds to the subpolar front; e.g., Rossby 1996; Dutkiewicz et al. 2001); second, outcropping of the light isopycnals due to atmospheric cooling through the process of Subpolar Mode Water formation on the warm side of the NAC-SPF-within the anticyclonic recirculating cells between the branches of the eastward flow associated with the SPF and in the Newfoundland Basin (McCartney and Talley 1982; Arhan 1990; Perez-Brunius et al. 2004b); and third, eddy mixing across the current along the NAC-SPF, which results in a net flux of subpolar waters into the subtropical side (Dutkiewicz et al. 2001).

The barotropic field (Fig. 6), on the other hand, is strongly influenced by the topography of the region. The location of the meanders of the northward-flowing NAC, the position of the Northwest Corner recirculation, and the crossing of the current through the MAR appear to be topographically controlled (Rossby 1996; Bower et al. 2002). The meanders set up recirculating cells: the Mann Eddy, a cyclonic circulation inshore of the NAC including a pronounced trough at $44.5^{\circ} \mathrm{N}$, and an extended anticyclonic recirculation east of Flemish Cap extending north to the Northwest Corner. The barotropic cyclonic and Flemish Cap-Northwest Corner recirculations substantially modify the more familiar baroclinic streamfunction field, giving shape to the absolute transport potential field. This results in flow across baroclinic contours, suggesting strong cross-frontal flow (Fig. 10). This is in agreement with particle exchange across a meandering front, as has been observed in the Gulf Stream. Water parcels entering a crest tend to flow up along their isopycnal surface, crossing the current from the warm to the cold side, while the opposite is true when the flow approaches a meander trough (Bower and Rossby 1989). The cross-frontal component is barotropic, induced by abyssal cyclones/anticylones that develop under troughs/crests (Lindstrom and Watts 1994; Savidge and Bane 1999; Howden and Watts 1999; Watts et al. 2001). This is analogous to the synoptic atmospheric systems produced by baroclinic instabilities under a baroclinic jet (e.g., Holton 1992). The lateral displacements lead to exchange between the current and surrounding waters (Song and Rossby 1995). If the meanders are steep, there is greater fluid exchange between the current and surrounding waters. Time variability in their amplitude also seems to enhance the exchange (Samelson 1992). It is interesting to note that the NAC is not baroclinically unstable (Kearns and Paldor 2000). Finding no unstable modes, Kearns and Paldor (2000) suggest that the meanders have a wavelength determined by the bathymetry and amplitudes with limited growth.

We argue that, regardless of the mechanism driving the meandering of the NAC or the Gulf Stream, the exchange processes induced by the meandering jet are similar, as suggested by our observations. Hence, we propose cross-frontal flow induced by the steep mean-

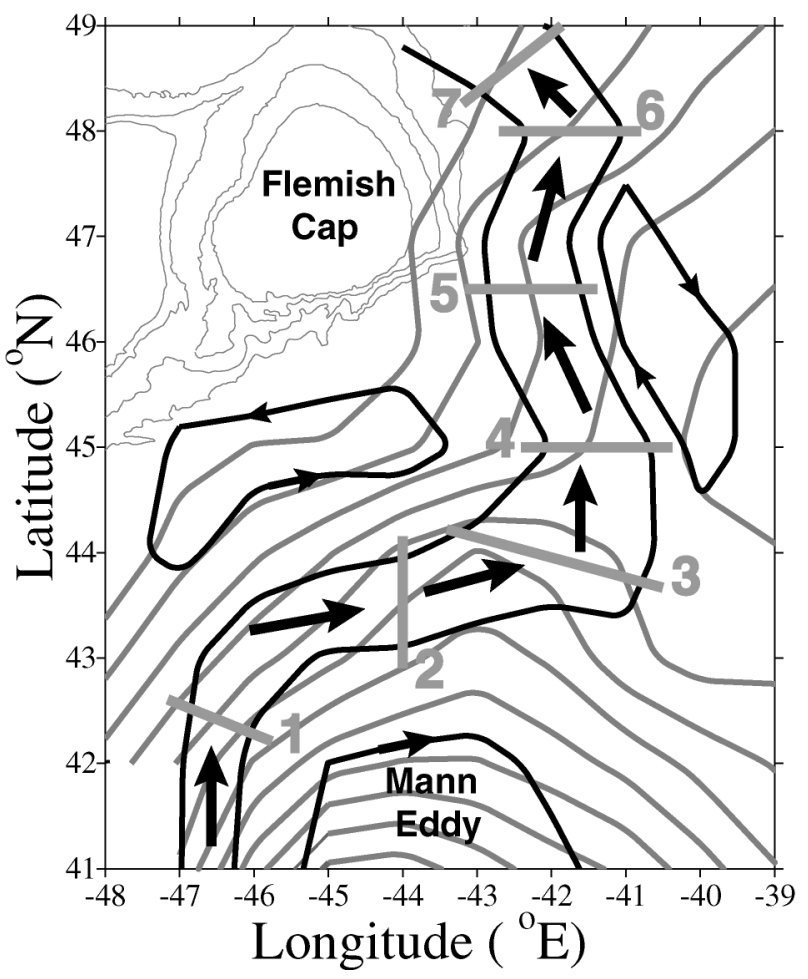

FIG. 10. Map of the streamfunctions on the $\delta$ surface of the floats, showing the mechanism of lateral exhange induced by the meanders of the northward-flowing NAC. The dark gray contours show the baroclinic streamfunction $\psi^{\text {bc }}$ (referenced to $1000 \mathrm{dbar}$, contour interval $3.33 \times 10^{-3} \mathrm{~m}^{2} \mathrm{~s}^{-1}$ ), the black contours show selected isolines of the absolute streamfunction $\psi^{\text {abs }}$, showing the NAC pipe and the recirculations cells surrounding it. The arrows show the direction of the flow along the current. Note how this flow is crossing baroclinic streamlines, resulting in lateral exchange across the stream (cold to warm from meander crests to troughs, warm to cold from troughs to crests).

ders of the NAC as the main mechanism that causes the patterns of heat loss (gain) between crests and troughs (troughs and crests) of the northward-flowing NAC (see Fig. 10). We estimate that $0.18 \pm 0.05 \mathrm{PW}$ are lost through this mechanism (Fig. 9b), which is 10 times the heat lost to the atmosphere in the northward segment of the pipe (order $0.02 \mathrm{PW}$, see section 4c). This suggests that most of the warm-to-cold transformation of the subtropical waters while passing through this region occurs along the northward-flowing NAC, through exchange of water parcels between the current and its surroundings.

Where does the heat lost by the NAC go? Part of the warm waters lost by the current feed the anticyclonic recirculations on its offshore side (the Mann Eddy and the Flemish Cap cells) and some of their heat may be lost to the atmosphere within the recirculations in wintertime, leading to the formation of mode water. Mode water of the warmest type has been observed within the Mann Eddy (e.g., Perez-Brunius et al. 2004b). Heat pumped into the recirculations may also be lost to the interior of the basin through eddy diffusion. The rest of 
the waters lost by the current to the subtropical side may diffuse back into the subtropical gyre, possibly feeding the Azores Current farther south, as suggested by Krauss et al. (1990). In this study, we estimate the mean heat flux of the NAC-SPF as the change in advection of temperature by the mean flow, assuming that those changes are due to the mean atmospheric fluxes and lateral exchange induced by the eddy field. It is important to note that, although the eddy field does not transport mass in the mean, it may contribute to the mean transport of tracers such as temperature along the current. Hence, it is possible that the actual mean heat fluxes are larger than suggested by our estimates or that they are partially compensated by the mean advection of temperature by the eddy field. The quantification of the contibution to the mean advection of temperature by the eddy field along the NAC-SPF is left for another study. Nevertheless, we note that the mean temperature of the current decreases by $\sim 4^{\circ} \mathrm{C}$ from the Tail of the Grand Banks to the Northwest Corner and remains at $\sim 7^{\circ} \mathrm{C}$ in the SPF section of the pipe, supporting the idea that most of the heat is lost in the northward-flowing NAC.

This study suggests that lateral exchange induced by the eddy field contributes significantly more than the atmosphere in cooling the subtropical waters in their transit toward the eastern subpolar North Atlantic. We note that most of the warm-to-cold transformation that results in deep convection takes place in the subpolar North Atlantic and in the convective sites of the Labrador and Nordic Seas, where the mixed layer reaches down to great depths in wintertime. Hence, the role of the atmosphere in the transformation process is likely to play a more significant role than horizontal mixing north of $53^{\circ} \mathrm{N}$. The conclusions of this study only apply to the transformation that takes place in the region upstream of the subpolar North Atlantic, that is, in the NAC-SPF conduct that connects the subtropical and subpolar regions of the North Atlantic.

The results of this study point out the importance of having direct measurements of the velocity in the NACSPF region since the streamlines inferred from hydrography alone do not reflect the pathways of flow in this area. Hence, analysis using baroclinic streamlines alone does not show as clearly the structure of the NAC-SPF as it evolves along its path from the Gulf Stream northeastward past the MAR, as part of the upper limb of the thermohaline circulation of the North Atlantic. With the advent of more realistic models for the region (e.g., Smith et al. 2000), it would be interesting to combine the float dataset presented here with model output to further study the processes of lateral exchange in the northward flowing NAC. Although the patterns that emerge seem similar to the ones on a baroclinically unstable current such as the Gulf Stream, further study is needed to understand lateral exchange in a current where the meanders remain fixed in space (i.e., do not propagate) and rarely grow large in amplitude.
Acknowledgments. The authors thank Jim Fontaine for building the floats, Sandra Anderson-Fontana for tracking them, and Peter Lazarevich, Mark Prater, and Huai-Min Zhang for subsequent data analysis and helpful discussions. Byron Willeford and Karen Tracey gave good tips for the GEM construction and horizontal mapping of the fields. Chris Meinen let us use his NAC section at $42^{\circ} \mathrm{N}$. Mark Prater and Mark Wimbush provided helpful suggestions for this manuscript. Paula Pérez-Brunius extends her gratitude to Amy Bower for support during the review period. Comments provided by two anonymous reviewers greatly improved the presentation of this study. This research was supported by the U.S. National Science Foundation under Grant OCE 99-06775. Paula Pérez-Brunius was supported by a graduate scholarship provided by the Consejo Nacional de Ciencia y Tecnología, México and a Fulbright-García Robles fellowship.

\section{APPENDIX A}

\section{Transport Errors}

The estimate of variable $\varphi$ obtained by binning the float-GEM data $\varphi^{\text {fg }}$ has an error $E^{t} \varphi$ given by

$$
E^{t} \varphi=\sqrt{\left(E^{\mathrm{fg}} \varphi\right)^{2}+\left(E^{b} \varphi\right)^{2}}
$$

where $E^{\mathrm{fg}} \varphi$ is the error associated with the float-GEM technique (Perez-Brunius et al. 2004a), and

$$
E^{b} \varphi=\frac{\sigma\left(\varphi^{\mathrm{fg}}\right)}{\sqrt{N}}
$$

is the standard error of the mean value $\varphi$ in the bin in question, $\sigma\left(\varphi^{\mathrm{fg}}\right)$ is the standard deviation of the floatGEM data in the bin, and $N$ is the number of observations in the bin.

Note that the binning error $E^{b}$ is smaller than the float-GEM error $E^{\mathrm{fg}}$.

\section{a. Mass transport errors}

The errors in the mass transport potentials calculated in section 3 are given by

$$
\begin{aligned}
& E^{t} Q_{1000}^{\mathrm{bc}}=\frac{E^{t} \chi}{f}, \\
& E^{t} Q_{1000}^{\mathrm{bt}}=\rho D E^{t} \Psi^{\mathrm{bt}}, \text { and } \\
& E^{t} Q_{1000}^{a}=\sqrt{\left(E^{t} Q_{1000}^{\mathrm{bc}}\right)^{2}+\left(E^{t} Q_{1000}^{\mathrm{bt}}\right)^{2}},
\end{aligned}
$$

where

$$
E^{t} \Psi^{\mathrm{bt}}=\sqrt{\left\{E^{t} \Psi^{a}\left[p\left(\delta_{f}\right)\right]\right\}^{2}+\left\{E^{t} \Psi^{\mathrm{bc}}\left[p\left(\delta_{f}\right)\right]\right\}^{2}},
$$

$E^{t} \Psi^{a}\left[p\left(\delta_{f}\right)\right]=\frac{\left(E U^{f} \Delta y+E V^{f} \Delta x\right)}{2}$,

$\rho=1027 \mathrm{~kg} \mathrm{~m}^{-3}$ is the mean density, $D=1000 \mathrm{~m}$ is the height of the water column, and $\left(E U^{f}, E V^{f}\right)$ are the 
TABLE A1. Errors involved in the mass transport potentials estimates. Note that the error due to binning $E^{b}$ is smaller than the error of the float-GEM $E^{\mathrm{fg}}$. Here $\|\mathbf{V}\|^{\mathbf{f}}$ is the magnitude of the velocity of the floats. The other terms are described in section 2.

\begin{tabular}{|c|c|c|c|}
\hline Variable & Error of the float-GEM technique $\left(E^{\mathrm{fg}}\right)$ & Error due to binning $\left(E^{b}\right)$ & Total error $\left(E^{t}\right)$ \\
\hline$\|\mathbf{V}\|^{\mathbf{f}}$ & $3.0 \mathrm{~cm} \mathrm{~s}^{-1}$ & $2.4 \mathrm{~cm} \mathrm{~s}^{-1}$ & $3.8 \mathrm{~cm} \mathrm{~s}^{-1}$ \\
\hline$U^{f}$ & $2.1 \mathrm{~cm} \mathrm{~s}^{-1}$ & $1.7 \mathrm{~cm} \mathrm{~s}^{-1}$ & $2.7 \mathrm{~cm} \mathrm{~s}^{-1}$ \\
\hline$V^{f}$ & $2.1 \mathrm{~cm} \mathrm{~s}^{-1}$ & $1.7 \mathrm{~cm} \mathrm{~s}^{-1}$ & $2.7 \mathrm{~cm} \mathrm{~s}^{-1}$ \\
\hline$\Psi^{a}\left[p\left(\delta_{f}\right)\right]$ & $30.0 \times 10^{2} \mathrm{~m}^{2} \mathrm{~s}^{-1}$ & $15.8 \times 10^{2} \mathrm{~m}^{2} \mathrm{~s}^{-1}$ & $32.1 \times 10^{2} \mathrm{~m}^{2} \mathrm{~s}^{-1}$ \\
\hline$\Psi^{\mathrm{bc}}\left[p\left(\delta_{f}\right)\right]$ & $6.3 \times 10^{2} \mathrm{~m}^{2} \mathrm{~s}^{-1}$ & $5.3 \times 10^{2} \mathrm{~m}^{2} \mathrm{~s}^{-1}$ & $8.2 \times 10^{2} \mathrm{~m}^{2} \mathrm{~s}^{-1}$ \\
\hline$\Psi_{\mathrm{bt}}$ & $28.6 \times 10^{2} \mathrm{~m}^{2} \mathrm{~s}^{-1}$ & $16.6 \times 10^{2} \mathrm{~m}^{2} \mathrm{~s}^{-1}$ & $33.1 \times 10^{2} \mathrm{~m}^{2} \mathrm{~s}^{-1}$ \\
\hline$Q_{1000}^{\mathrm{bc}}$ & $1.0 \mathrm{SV}$ & $0.5 \mathrm{~Sv}$ & $1.2 \mathrm{~Sv}$ \\
\hline$Q_{1000}^{\mathrm{bt}}$ & $2.9 \mathrm{~Sv}$ & $1.7 \mathrm{~Sv}$ & $3.3 \mathrm{~Sv}$ \\
\hline$Q_{1000}^{a}$ & $3.0 \mathrm{~Sv}$ & $1.8 \mathrm{~Sv}$ & $3.5 \mathrm{~Sv}$ \\
\hline
\end{tabular}

errors in the east- and northward velocities measured by the RAFOS floats, respectively. Equations (A5) and (A6) assume that the errors in the baroclinic and barotropic components are uncorrelated. The bins are $1^{\circ} \times 1^{\circ}$, which results in $\Delta x \approx 75 \mathrm{~km}$ in the east-west direction and $\Delta y=111 \mathrm{~km}$ in the north-south direction. Table A1 shows the mean values of the errors mentioned above for the NAC-SPF region.

\section{b. Absolute temperature transport error}

The errors in the absolute temperature transports for the NAC-SPF pipe calculated in section 4 are given by

$$
E^{t} H_{1000}=\rho C_{p} D \bar{T} \bar{V} \Delta x \sqrt{\left(\frac{E T}{\bar{T}}\right)^{2}+\left(\frac{E V}{\bar{V}}\right)^{2}},
$$

where $C_{p}=4000 \mathrm{~J} \mathrm{~kg}^{-1{ }^{\circ}} \mathrm{C}^{-1}$ is the specific heat of seawater, $\bar{T}=7.4^{\circ} \mathrm{C}$ is the mean temperature, $\bar{V}=10$ $\mathrm{cm} \mathrm{s}^{-1}$ is the mean speed of the waters within the NACSPF pipe, $\Delta x=25 \mathrm{~km}$ is the station spacing used for the transects, and

$$
\begin{aligned}
& E^{t} T=\sqrt{\left(E^{\mathrm{fg}} T\right)^{2}+\left(E^{b} T\right)^{2}} \text { and } \\
& E^{t} V=\sqrt{\left(E^{\mathrm{fg}} V\right)^{2}+\left(E^{b} V\right)^{2}}
\end{aligned}
$$

are the corresponding mean errors for temperature and velocity, respectively. The errors have the following values: $E^{\mathrm{fg}} T=0.33^{\circ} \mathrm{C}, E^{b} T=0.35^{\circ} \mathrm{C}, \Rightarrow E^{t} T=0.46^{\circ} \mathrm{C}$; and $E^{\mathrm{fg}} V=4.7 \mathrm{~cm} \mathrm{~s}^{-1}, E^{b} V=5.1 \mathrm{~cm} \mathrm{~s}^{-1}, \Rightarrow E^{t} V=$ $9.9 \mathrm{~cm} \mathrm{~s}^{-1}$. This results in an error $E^{t} H_{1000}=0.05 \mathrm{PW}$ for the absolute temperature transport.

\section{APPENDIX B}

\section{Objective Analysis}

This appendix describes the multivariate objective analysis (OA) used to interpolate and smooth a binned field $\varphi\left(x_{b}, y_{b}, p\right)$, adapted from the procedure presented in Watts et al. (2001). The covariance function is assumed to be a Gaussian with an $e$-folding length scale of $R$. We apply a first pass of the OA, using $R_{b}$ as the correlation length scale, to obtain a smooth "background" field $\varphi_{\mathrm{bg}}^{\mathrm{OA}}\left(x_{b}, y_{b}, p\right)$. This mean field is sub- tracted from the binned field, and the residuals are obtained:

$$
\varphi_{\text {res }}\left(x_{b}, y_{b}\right)=\varphi\left(x_{b}, y_{b}\right)-\varphi_{\mathrm{bg}}^{\mathrm{OA}}\left(x_{b}, y_{b}\right),
$$

where the subscript OA is used to distinguish the objectively mapped fields from the binned fields. Applying a second pass of the OA to $\varphi_{\text {res }}$, with $R_{r}<R_{b}$ to resolve the smaller scales, the residual field is mapped on the desired grid $\left\{x_{i}, y_{i}\right\} \subseteq\left\{x_{b}, y_{b}\right\}$. Stammer (1997) calculated the regional covariance functions for the Atlantic from altimeter data and found that the zero-crossing of the covariance functions is a function of the radius of deformation. The radius of deformation for our region of study is around 20-30 km (Chelton et al. 1998), which corresponds to a zero crossing of $\sim 90 \mathrm{~km}$. We use this value as the approximate correlation length scale $R$ for the region.

The final fields are then given by

$$
\varphi^{\mathrm{OA}}\left(x_{i}, y_{i}, p\right)=\varphi_{\mathrm{bg}}^{\mathrm{OA}}\left(x_{i}, y_{i}, p\right)+\varphi_{\mathrm{res}}^{\mathrm{OA}}\left(x_{i}, y_{i}, p\right) \text {. }
$$

\section{REFERENCES}

Anderson-Fontana, S., M. Prater, and H. T. Rossby, 1996: RAFOS float data report of the North Atlantic Current study 1993-1995. GSO Tech. Rep. 96-4, Graduate School of Oceanography, University of Rhode Island, $241 \mathrm{pp}$.

— , P. Lazarevich, P. Perez-Brunius, M. Prater, T. Rossby, and H.-M. Zhang, 2001: RAFOS float data report of the Atlantic Climate Change Experiment (ACCE), 1997-2000. GSO Tech. Rep. 01-4, Graduate School of Oceanography, University of Rhode Island, $112 \mathrm{pp}$.

Arhan, M., 1990: The North Atlantic Current and Subarctic Intermediate Water. J. Mar. Res., 48, 109-144.

Belkin, I. M., and S. Levitus, 1996: Temporal variability of the subarctic front near the Charlie-Gibbs Fracture Zone. J. Geophys. Res., 101, 28 317-28 324.

Bower, A. S., and T. Rossby, 1989: Evidence of cross-frontal exchange processes in the Gulf Stream based on isopycnal RAFOS float data. J. Phys. Oceanogr., 19, 1177-1190.

—_ and Coauthors, 2000: Warm-water pathways in the subpolar North Atlantic: An overview of the ACCE RAFOS float programme. Int. WOCE Newslett. No. 38, WOCE International Project Office, Southampton, United Kingdom, 14-16.

— , and Coauthors, 2002: Directly measured mid-depth circulation in the northeastern North Atlantic Ocean. Nature, 419, 603-607.

Bretherton, F. P., R. E. Davis, and C. B. Fandry, 1976: The technique for objective analysis and design of oceanographic experiments applied to MODE-73. Deep-Sea Res., 23, 559-582. 
Bubnov, V. S., 1995: The North Atlantic Current by the Atlantex 90 Experiment data. Oceanology, 34, 733-737.

Carr, M. E., E. J. Kearns, and H. T. Rossby, 1997: Isopycnal RAFOS floats as roving hydrographers in the North Atlantic Current region. Geophys. Res. Lett., 24, 551-554.

Chelton, D. B., R. A. deSzoeke, M. G. Schlax, K. E. Naggar, and N. Siwertz, 1998: Geographical variability of the first baroclinic Rossby radius of deformation. J. Phys. Oceanogr., 28, 433-460.

Clarke, R. A., T. Rossby, R. Watts, and I. M. Yashayev, 1996: The North Atlantic Current and Polar Front revisited: The WOCE control volume experiment in the Newfoundland Basin, 19931995. ICES Contributions to Statutory Meetings, Theme Session on the North Atlantic Components of Global Programmes: Lessons to ICES-GLOBEC from WOCE/JGOFS, ICES Council Meeting Papers 1996/O:5, 17 pp.

Curry, R. G., 1996: HydroBase-A database for hydrographic stations and tools for climatological analysis. Woods Hole Oceanographic Institution Tech. Rep. WHOI-96-01, 44 pp.

Dietrich, G., K. Kalle, W. Krauss, and G. Siedler, 1980: General Oceanography: An Introduction. 2d ed. John Wiley and Sons, $626 \mathrm{pp}$. (Translated from the German by Susanne Roll and Itans Ulrich Roll.)

Dutkiewicz, S., L. Rothstein, and T. Rossby, 2001: Pathways of crossfrontal exchange in the North Atlantic Current. J. Geophys. Res. 106, $26917-26928$

Fofonoff, N. P., 1962: Physical properties of sea-water. The Sea, N. M. Hill, Ed., Physical Oceanography, Vol. 1, John Wiley and Sons, 3-30.

Fratantoni, D. M., 2001: North Atlantic surface circulation during the 1990s observed with satellite tracked drifters. J. Geophys. Res. 106, 22 067-22 093.

Holton, J. R., 1992: An Introduction to Dynamical Meteorology. Academic Press, $511 \mathrm{pp}$

Howden, S. D., and R. D. Watts, 1999: Jet streaks in the Gulf Stream. J. Phys. Oceanogr., 29, 1910-1924.

Iselin, C. O., 1936: A study of the circulation of the western North Atlantic. Pap. Phys. Oceanogr. Meteor., 4 (4), 1-101.

Kalnay, E., and Coauthors, 1996: The NCEP/NCAR 40-Year Reanalysis Project. Bull. Amer. Meteor. Soc., 77, 437-471.

Kearns, E. J., 1996: A description of the North Atlantic Current system from historical hydrography. Ph.D. thesis, University of Rhode Island, $189 \mathrm{pp}$

- and H. T. Rossby, 1998: Historical position of the North Atlantic Current. J. Geophys. Res., 103, 15 509-15 524.

- and N. Paldor, 2000: Why are the meanders of the North Atlantic Current stable and stationary? Geophys. Res. Lett., 27, 1029-1032.

Krauss, W., 1986: The North Atlantic Current. J. Geophys. Res., 91, 5061-5074.

—, E. Fahrbach, A. Aitsam, J. Elken, and P. Loske, 1987: The North Atlantic Current and its associated eddy field southeast of Flemish Cap. Deep-Sea Res., 34, 1163-1185.

- R. H. Käse, and H. H. Heinrichsen, 1990: The branching of the Gulf Stream southeast of the Grand Banks. J. Geophys. Res., 95, 13 089-13 103.

LaViolette, P., 1983: The Grand Banks Experiment: A satellite/aircraft/ship experiment to explore the ability of specialized radars to define ocean fronts. NORDA Tech. Rep. 49, Naval Oceanographic and Atmospheric Research Laboratory, Stennis Center, MS, $116 \mathrm{pp}$

Lazier, J. R. N., 1994: Observations in the Northwest Corner of the North Atlantic Current. J. Phys. Oceanogr., 24, 1449-1463.

Lindstrom, S. S., and D. R. Watts, 1994: Vertical motion in the Gulf Stream near $68^{\circ}$ W. J. Phys. Oceanogr., 24, 2321-2333.

Lozier, S., W. Owen, and R. Curry, 1995: The climatology of the
North Atlantic. Progress in Oceanography, Vol. 36, Pergamon, $1-44$

McCartney, M. S., and L. D. Talley, 1982: The subpolar mode water of the North Atlantic Ocean. J. Phys. Oceanogr., 12, 1169-1188.

McDougall, T. J., 1989: Streamfunctions for the lateral velocity vector in a compressible ocean. J. Mar. Res., 47, 267-284.

Meinen, C. S., 2001: Structure of the North Atlantic Current in stream-coordinates and the circulation in the Newfoundland Basin. Deep-Sea Res., 48A, 1553-1580.

_ transect across the North Atlantic Current near $42^{\circ} \mathrm{N}$ : Time series and mean. J. Geophys. Res., 105, 21 869-21 891.

, -, and R. A. Clarke, 2000: Absolutely referenced geostrophic velocity and transport on a section across the North Atlantic Current. Deep-Sea Res., 47A, 309-322.

Perez-Brunius, P., 2002: The North Atlantic Current-subpolar front system: A study combining float data and historical hydrography. Ph.D. thesis, University of Rhode Island, $165 \mathrm{pp}$.

— T. Rossby, and R. D. Watts, 2004a: A method to obtain the mean transports of ocean currents by combining isopycnal float data with historical hydrography. J. Atmos. Oceanic Technol., 21, 298-316.

$-\ldots,-$ and $-2004 \mathrm{~b}$ : Transformation of the warm waters of the North Atlantic from a geostrophic streamfunction perspective. J. Phys. Oceanogr., in press.

Reiniger, R. F., and R. A. Clarke, 1975: Circulation pattern in the Newfoundland ridge area, 1972. Proc. Symp. on Environmental Conditions in the Newfoundland Grand Bank Area in 1972 and Their Effect on Fishery Trends, Dartmouth, Nova Scotia, International Commission for the Northwest Atlantic Fisheries, Special Publication No. 10, 57-67.

Reverdin, G., P. P. Niiler, and H. Valdimarsson, 2003: North Atlantic Ocean surface currents. J. Geophys. Res., 108, 3002, doi: 10.1029/2001JC001020.

Rossby, T., 1996: The North Atlantic Current and surrounding waters: At the crossroads. Rev. Geophys., 34, 463-481.

Samelson, R. M., 1992: Fluid exchange across a meandering jet. $J$. Phys. Oceanogr., 22, 431-440.

Savidge, D. K., and J. M. Bane, 1999: Cyclogenesis in the deep ocean beneath the Gulf Stream: 1. Description. J. Geophys. Res., 104, $18111-18126$

Smith, R. D., M. E. Maltraud, F. O. Bryan, and M. W. Hecht, 2000: Numerical simulation of the North Atlantic Ocean at $1 / 10^{\circ} . J$. Phys. Oceanogr., 30, 1532-1561.

Song, T., and T. Rossby, 1995: Lagrangian studies of fluid exchange between the Gulf Stream and surrounding patterns. J. Phys. Oceanogr., 25, 46-63

Stammer, D., 1997: Global characteristics of ocean variability estimated from regional TOPEX/Poseidon altimeter measurements. J. Phys. Oceanogr., 27, 1743-1769.

Sun, C., 2001: The columnar structure of stratified geostrophic flows. Geophys. Astrophys. Fluid Dyn., 95, 55-65.

- and R. Watts, 2001: A circumpolar Gravest Empirical Mode for the Southern Ocean hydrography. J. Geophys. Res., 106, 2833-2856.

Sy, A., 1988: Investigation of large-scale circulation patterns in the central North Atlantic: The North Atlantic Current, the Azores Current, and the Mediterranean Water plume in the area of the Mid-Atlantic Ridge. Deep-Sea Res., 35, 383-413.

__ U. Schauer, and J. Meincke, 1992: The North Atlantic Current and its associated hydrographic structure above and eastwards of the Mid-Atlantic Ridge. Deep-Sea Res., 39, 825-853.

Watts, D. R., X. Qian, and K. L. Tracey, 2001: Mapping abyssal current and pressure fields under the meandering Gulf Stream. J. Atmos. Oceanic Technol., 18, 1052-1067.

Zhang, H. M., M. D. Prater, and T. Rossby, 2001: Isopycnal Lagrangian statistics from the North Atlantic Current RAFOS float observations. J. Geophys. Res., 106, 13 817-13 836. 